BULLETIN Bulletin hispanique

HispaniquE Université Michel de Montaigne Bordeaux

119-1 | 2017

Autorité et pouvoir dans le théâtre du Siècle d'Or

\title{
La figura del rey en el teatro de Enríquez Gómez
}

\section{Rafael González Cañal}

\section{(2) OpenEdition}

\section{Journals}

Edición electrónica

URL: http://journals.openedition.org/bulletinhispanique/4851

DOI: 10.4000/bulletinhispanique.4851

ISBN: 979-10-300-0142-6

ISSN: 1775-3821

\section{Editor}

Presses universitaires de Bordeaux

\section{Edición impresa}

Fecha de publicación: 15 junio 2017

Paginación: 187-202

ISBN: 979-10-300-0141-9

ISSN: 0007-4640

Referencia electrónica

Rafael González Cañal, « La figura del rey en el teatro de Enríquez Gómez », Bulletin hispanique [En línea], 119-1 | 2017, Publicado el 15 junio 2020, consultado el 11 septiembre 2020. URL : http:// journals.openedition.org/bulletinhispanique/4851; DOI : https://doi.org/10.4000/bulletinhispanique. 4851 


\title{
La figura del rey en el teatro de Enríquez Gómez ${ }^{1}$
}

\author{
Rafael González Cañal \\ Universidad de Castilla-La Mancha
}

Les préoccupations politiques de l'écrivain judéo-convers Antonio Enríquez Gómez, présentes dans certains de ses écrits en prose composés durant son exil en France, sont aussi perceptibles dans son théâtre. De nombreuses pièces ont pour protagonistes des rois, des princes ou des favoris aux comportements discutables. Larticle présente l'analyse de quelques-unes de ces pièces et une synthèse de la pensée politique qui, disséminée çà et là, s’y fait jour.

Mots-clés : Enríquez Gómez, comédie, monarchie, pouvoir, favori, idées politiques.

La preocupación política del escritor judeoconverso Antonio Enríquez Gómez, que se muestra en algunas de sus obras en prosa escritas durante su exilio en Francia, se detecta también en su teatro. Un buen número de sus comedias están protagonizadas por reyes, príncipes y validos que presentan comportamientos más o menos dignos o censurables. Analizamos algunas de estas comedias y recogemos las ideas recurrentes de su pensamiento político allí diseminadas.

Palabras-clave: Enríquez Gómez, comedia, monarquía, poder, privado, ideas políticas.

The political concerns of Jewish convert writer Antonio Enríquez Gómez - displayed in some of his prose works written while in France - are also perceptible in his dramatic production. Several of his comedies deal with kings, princes, and favourites, whose behaviour is more or less ethical or censurable. This article discusses some of these comedies and compiles recurrent political ideas disseminated within his dramatic work.

Keywords: Enríquez Gómez, comedie, monarchy, power, favorite, political ideas.

1. Este trabajo se inscribe dentro del proyecto de investigación Edición y estudio de la obra de Antonio Enríquez Gómez y Felipe Godinez, II (FFI2014-54376-C03-1-P) y de la Red del Patrimonio Teatral Clásico Español (FFI2015-71441-REDC) del Programa Estatal Redes de Excelencia del Ministerio de Economía y Competitividad. 
Tos estudios sobre la autoridad y el poder en el teatro del Siglo de Oro han aumentado de manera excepcional en los últimos tiempos². Es indudable que este tema aparece íntimamente ligado a la acción dramática de muchas de las comedias áureas. Abundan, pues, los argumentos que tratan del arte del buen gobierno, que reflexionan sobre los mecanismos del poder o que analizan los diversos comportamientos de reyes y privados. Además, la figura del rey es una preocupación fundamental de los tratadistas y teóricos de la política de esta época.

Uno de los objetivos de los escritores del siglo XVII era presentar un modelo de gobernante ideal que pudiera rescatar al país de la grave crisis en la que estaba sumido. Así, se va a ofrecer una imagen concreta de los reyes y de su manera de actuar en la sociedad que gobiernan. Como expone Cañas Murillo $^{3}$, la visión del rey en la comedia nueva deriva del código denominado «teocentrismo monárquico " o «monarquía teocéntrica», que propugna que el poder que detenta el rey proviene de Dios, configurándolo como un vicediós en la tierra. Ya lo señalaba Pedro de Rivadeneira en 1595 en su Tratado de la religión y virtudes que debe tener el príncipe cristiano...:

...que los príncipes cristianos entiendan que toda la potestad que tienen es de Dios, y que Él se la dio porque sus súbditos sean bienaventurados acá con felicidad temporal (que es a lo que se endereza el gobierno político), y allá con la eterna, a la cual nuestra temporal mira y se endereza como su blanco y último fin. ${ }^{4}$

Este carácter divino de la monarquía, heredado de los tratadistas medievales, aparece inevitablemente unido a la reflexión sobre la naturaleza del poder político. El punto de partida se fundamentaba en dos conocidos pasajes bíblicos: «Per me reges regnant» (Proverbios, 8,15$)^{5} \mathrm{y}$ «Non est potestas nisi a Deo» (Romanos, 13, 1). Por ejemplo, Francisco de Vitoria, en De potestate civili (1528), al analizar la fundamentación del poder, señala que el poder político, por ser algo que se sigue de la naturaleza del hombre, procede de Dios mismo, pero se inscribe en una comunidad. Un humanista como Pedro de Valencia sigue defendiendo hacia 1618 el origen divino del poder temporal,

2. Vid. Autoridad y poder en el siglo de Oro, eds. I. Arellano, C. Strosetzki y E. Williamson, Madrid, Iberoamericana, 2009; Ignacio Arellano, Los rostros del poder en el siglo de Oro: Ingenio y espectáculo, Sevilla, Renacimiento, 2011; El universo simbólico del poder en el Siglo de Oro, ed. A. Baraibar y M. Insúa, Nueva York/ Pamplona, Instituto de Estudios Auriseculares (IDEA)/ Universidad de Navarra, 2012; y Teatro y poder en el Siglo de Oro, ed. M. Insúa y F. K. E. Schmelzer, Pamplona, Universidad de Navarra, 2013.

3. Jesús Cañas Murillo, «El rey y la monarquía en las comedias de Francisco Bances Candamo», Archivum, LXI-LXII, 2011-2012, p. 81-82.

4. Pedro de Rivadeneira, Tratado de la religión y virtudes que debe tener el príncipe cristiano, en Obras escogidas, ed. Vicente de la Fuente, Madrid, Rivadeneyra, 1868, p. 459.

5. Así lo señala el arzobispo de Toledo en El rey más perfecto de Enríquez Gómez: «los reyes por Dios gobiernan» (The Perfect King: El rey más perfeto, ed. and trans. Michael Mcgaha, Tempe, Arizona, Bilingual Press, 1991, p. 18). Sobre este tema, vid. Antonio Feros, "Vicedioses, pero humanos”: el drama del rey», Cuadernos de Historia Moderna, 14, 1993, p. 103-131. 
dado a los reyes «por unción, espíritu y valor comunicado de Dios» ${ }^{6}$. Por eso los reyes han de imitar a Cristo, el rey perfecto, idea recurrente, por ejemplo, en la Política de Dios de Quevedo7. No obstante, el propio Pedro de Valencia precisa que, como no siempre es posible tener un príncipe justo y sabio, ya que llega al poder "por nacimiento y estados», debe guardar la ley, es decir, debe tener un poder limitado, «sujeto a las leyes, obligado a tomar consejo y subordinado a la justicia y a la pública utilidad». En este punto se separa de la mayoría de los tratadistas políticos de la época para los que el rey se hallaba por encima de las leyes y solo podía ser juzgado por Dios. Sin embargo, para el humanista extremeño, el poder real queda limitado por las Cortes, que representan a todos los estamentos de la sociedad, de tal manera que la soberanía reside en la comunidad. En la misma línea se encuentra también Juan de Mariana que afirmaba que el poder real no era ilimitado y debía estar sometido a las leyes:

Puesto que el poder real, si es legítimo, ha sido creado por consentimiento de los ciudadanos y solo por este medio pudieron ser colocados los primeros hombres en la cumbre de los negocios públicos, ha de ser limitado desde un principio por leyes y estatutos, a fin de que no se exceda en perjuicio de sus súbditos y degenere al fin en tiranía. ${ }^{8}$

Incluso llega a defender la posibilidad del regicidio cuando el rey traiciona el pacto que lo une al pueblo y se convierte en tirano. La polémica sobre los límites del poder del monarca se mantiene muy viva en la primera mitad del siglo XVII.

Otra de las preocupaciones principales de los escritores políticos de la España de la Austrias es el tema de la educación del príncipe como base para un futuro buen gobierno del reino. En la comedia española aparecen una y otra vez conflictos en torno al poder real, a la figura del rey y a la formación del príncipe. Los monarcas suelen protagonizar principalmente comedias de tema histórico, aunque también en el género denominado comedia palatina son frecuentes las tramas protagonizadas por reyes, príncipes y validos, eso sí, desarrolladas en cortes lejanas y en épocas imprecisas.

Felipe B. Pedraza' establece una útil clasificación del personaje del rey en la comedia espańola, a partir de su carácter. Presenta tres tipos de monarcas:

6. "Consideraciones acerca de enfermedades y salud del reino», en Pedro de Valencia, Escritos sociales. 2. Escritos políticos, ed. Rafael González Cañal, Rafael Carrasco, Gaspar Morocho e Hipólito B. Riesco León, Universidad de León, 1999, f. 124v-125r.

7. «Obligado estáis a la imitación de Cristo» (Francisco de Quevedo, Política de Dios. Gobierno de Christo, ed. James O. Crosby, Urbana, University of Illinois Press, 1966, p. 165).

8. Juan de Mariana, Del rey y la institución real, en Obras, II, ed. Francisco Pi y Margall, Madrid, Atlas, 1950, p. 485.

9. Felipe B. Pedraza Jiménez, "Reyes de comedia. El caso de El Burlador... y otros casos», en En buena compañia. Estudios en honor de Luciano García Lorenzo, coord. Joaquín Álvarez Barrientos et al., Madrid, CSIC, 2009, p. 535- 546. Recuérdese que ya Francisco Ruiz Ramón había distinguido entre el rey viejo, que representaba el ejercicio de la prudencia y el rey-galán, gobernado por las pasiones y caracterizado por la soberbia y la injusticia (Francisco Ruiz Ramón, Historia del teatro español, Madrid, Alianza, 1967, I, p. 152.). 
- El rey benigno y débil, desbordado por la lucha por el poder que le rodea.

- El rey tirano, cuya conducta se caracteriza por la opresión y el abuso que desemboca a veces en una reacción en el reino, que termina en ocasiones en tiranicidio o regicidio. A veces se trata de un galán que se deja llevar por sus apetitos y pasiones.

- El rey justiciero, que destaca como modelo de ejercicio de poder en favor del pueblo. Como rey justo castiga al final de la comedia las ofensas, abusos y delitos que se han producido.

Esta clasificación nos da una idea aproximada del abanico de posibilidades que podemos encontrar en el corpus dramático del siglo XVII en cuanto a la caracterización del personaje real. Sea como ejemplo modélico o como contraejemplo negativo, las comedias protagonizadas por los reyes componen una especie de ars gubernandi que proporciona, directa o indirectamente, una descripción de las cualidades y virtudes que deben caracterizar al buen monarca.

El rey va a resultar una figura clave en el teatro de Antonio Enríquez Gómez ${ }^{10}$. El interés que tenía el escritor conquense en temas de política y gobierno, como se aprecia en algunas de sus obras en prosa ${ }^{11}$, le lleva a componer obras dramáticas en donde la reflexión sobre el poder real, el comportamiento del príncipe y la figura del valido serán una constante. También la búsqueda de la justicia será una de sus grandes preocupaciones. En muchos casos nos encontraremos con el conflicto entre la pasión de un príncipe y los intereses o razón de estado. Así, desfilan por sus comedias reyes o príncipes gobernados por las pasiones, guiados por sus sentimientos amorosos y por los celos derivados de ellos, lo que les aleja de sus obligaciones y les lleva a comportarse de manera poco decorosa. Saavedra Fajardo, en su Idea de un príncipe político cristiano (1640), aconseja a estos príncipes y monarcas que se guíen por la razón y no se dejen arrastrar por sus apetitos:

Porque si se consideran bien las caídas de los imperios, las mudanzas de los estados y las muertes violentas de los príncipes, casi todas han nacido de la inobediencia de los afectos y pasiones a la razón. No tiene el bien público mayor enemigo que a ellas y a los fines particulares. ${ }^{12}$

El propio Enríquez Gómez recomendaba a los reyes el dominio de las pasiones para alcanzar el buen gobierno: «Nacen los reyes señores de sus vasallos, pero no señores de sus pasiones; estas se deben vencer, si aquellos gobernar.» ${ }^{13}$

10. Un análisis de la figura del rey en distintas comedias del Siglo de Oro puede verse en $E l$ teatro clásico español a través de sus monarcas, ed. Luciano García Lorenzo, Madrid, Fundamentos, 2006.

11. En Luis dado de Dios a Luis y Ana... (Paris, René Baudry, 1645) y en la Política angélica (Rouan, L. Maurry, 1647) detalla su teoría política.

12. Diego Saavedra Fajardo, Empresas politicas, ed. Francisaco Javier Díez de Revenga, Barcelona, Planeta, 1988, p. 57.

13. Antonio Enríquez Gómez, Luis dado de Dios..., op. cit., p. 3. 
Como señala Constance Rose «casi toda la obra de Enríquez Gómez es un reloj de príncipes en que ofrece su consejo al rey español ${ }^{14}$. Por eso, en algunas de sus obras dramáticas aparecen reflexiones sobre cómo debe ser el buen rey. Por ejemplo, en Amor con vista y cordura asistimos al conflicto entre el emperador Marco Aurelio y el príncipe Cómodo y se alude a algunas de las virtudes y cualidades que debe tener un monarca. Así, debe conocer los problemas del reino y para ello debe salir y no quedarse en palacio:

Los reyes que están guardados

en su palacio no son

reyes nunca, y si lo son,

son reyes emparedados. ${ }^{15}$

El príncipe debe adquirir una buena formación en las armas y las letras, evitando caer en el ocio:

$$
\begin{aligned}
& \text { El príncipe que ocupado } \\
& \text { estuviere en alegría, } \\
& \text { perderá la monarquía } \\
& \text { cuando esté más descuidado. } \\
& \text { Armas y letras los reyes } \\
& \text { deben estudiar, que son } \\
& \text { la divina estimación } \\
& \text { de las soberanas leyes. }{ }^{16}
\end{aligned}
$$

En La montañesa de Burgos el rey se siente un «Argos vigilante» de su reino. Además, el dramaturgo utiliza la tópica comparación con el sol para describir al monarca :

$$
\begin{aligned}
& \text { En un rey es importante } \\
& \text { la vigilia y el desvelo } \\
& \text { para saber gobernar, } \\
& \text { pues tiene el mismo lugar } \\
& \text { que tiene el sol en el cielo, } \\
& \text { comunicando, señor, } \\
& \text { a su imperio sin segundo } \\
& \text { los rayos, como hace al mundo } \\
& \text { ese planeta mayor. }{ }^{17}
\end{aligned}
$$

La imagen que se proyecta del rey en sus obras es la de un rey justo, prudente y que busca el amor se sus súbditos, tal y como señala el arzobispo D. Rodrigo en El rey más perfecto:

14. Constance Rose, "Las comedias políticas de Antonio Enríquez Gómez», Nuevo Hispanismo, 2, 1982, p. 47; vid. también Michèle Gendreau-Massaloux y Constance H. Rose, «Antonio Enriquez Gómez et Manuel Fernandes Villareal: Deux destins parallèles, une vision politique commune», Revue des Études Juives, 136, 1977, p. 368-387.

15. Amor con vista y cordura, ed. Almudena García, en A. Enríquez Gómez, Academias morales de las Musas, ed. Milagros Rodríguez Cáceres y Felipe B. Pedraza Jiménez, Cuenca, Universidad de Castilla-La Mancha, 2015, II, p. 399.

16. Ibid., p. 411.

17. La montañesa de Burgos, Madrid, BNE, ms. 14900, f. 22v. 
Los reyes siempre tuvieron por firme razón de estado, si son justos y prudentes, el honrar a sus vasallos. ${ }^{18}$

Pero también los vasallos deben respetar y obedecer al monarca, como se advierte en No hay contra el honor poder:

pero el noble y el vasallo
que se precia de leal,
por su materia de estado,
la honra y reputación
del monarca es el sagrado
que ha de venerar primero.

Otras virtudes y cualidades que deben caracterizar al buen rey se exponen con más claridad en Luis dado de Dios. . . l la práctica de la justicia («No se hacen temer tanto los reyes con el poder como con la justicia»), la prudencia ( $\mathrm{El}$ monarca prudente primero se aconseja con Dios que con su consejo») y el amor y benevolencia («Los mayores imperios se conquistaron con el amor, obrando más la benignidad del príncipe que la espada») ${ }^{20}$.

Dentro del corpus de este dramaturgo encontramos una veintena de obras en las que aparece la figura de un rey o un príncipe. Los monarcas aparecen principalmente en dos géneros: las comedias palatinas y las historiales ${ }^{21}$. Cinco comedias palatinas de Enríquez Gómez cuentan con el personaje del rey con mayor o menor protagonismo ${ }^{22}$ : Engañar para reinar, Celos no ofenden al sol, A lo que obligan los celos, Mudarse por mejorarse y Quien habla más obra menos.

Los protagonistas de estas comedias suelen pertenecer a la alta escala social. Los nombres y los títulos sirven para reforzar la verosimilitud. Así, nos encontramos con reyes, príncipes, duques o caballeros y damas de cortes lejanas e imprecisas inmersos en complicados enredos amorosos. Sus tramas nos permiten reflexionar sobre la conducta de reyes, príncipes y validos, y sobre los distintos mecanismos del poder. Así, hallamos todo un abanico de comportamientos regios: aparece, por ejemplo, el conflicto y pugna por la corona entre dos hermanos poco ejemplares (Engañar para reinar); un rey viejo, preocupado por su sucesión y tratando de contener las pasiones impetuosas de un príncipe mudable y enamoradizo (Mudarse por mejorarse); otro rey, burlador en su juventud de una dama, que se reencuentra casualmente con ella y que, al

18. El rey más perfeto, op. cit., p. 142.

19. No hay contra el honor poder, en Segunda parte de comedias escogidas..., Madrid, Imprenta Real, 1652, f. 323r.

20. Luis dado de Dios..., op. cit., p. 3, 7 y 115, respectivamente.

21. No trataremos aquí la figura del tirano que aparece en una de sus comedias bíblicas ( $\mathrm{La}$ soberbia de Nembrot) o el personaje del rey que aparece en una de sus comedias de santos ( $\mathrm{La}$ defensora de la reina de Hungría).

22. Rafael González Cañal y Alberto Gutiérrez Gil, «Las comedias palatinas de Rojas Zorrilla y Enríquez Gómez», en La comedia palatina del Siglo de Oro, coord. Miguel Zugasti, Cuadernos de Teatro Clásico, 30, 2015, p. 153-177. 
final, descubre que tiene además un hijo (A lo que obligan los celos); un monarca sensato y prudente que se enfrenta a la rivalidad entre un príncipe traidor y su nuevo favorito (Celos no ofenden al sol); e incluso un rey íntegro y generoso que renuncia a su pasión por una dama para que se case con su verdadero amor (Quien habla más obra menos).

Probablemente, la primera obra que compuso Enríquez Gómez, hacia 1632, fue la titulada Engañar para reinar. La comedia está protagonizada por Iberio, rey de Hungría, prometido con su prima Isbela, pero que se enamora de una dama llamada Elena que vive retirada en una quinta. Al final de la primera jornada, el rey se casa en secreto con Elena, renuncia al reino y se queda a vivir escondido en la quinta. Al creer a Iberio muerto, se proclama rey su hermano Ludovico que, a su vez, trata de casarse con Isbela, pero es rechazado. Tres años después, ante la tiranía y arrogancia del nuevo rey Ludovico, los nobles van en busca de Iberio y, tras numerosas vicisitudes, se produce un enfrentamiento directo entre los dos hermanos, siendo Iberio el vencedor. Al final, este hace que Isbela se case con el soberbio Ludovico y le da parte del reino, mientras él sube al trono con Elena.

Así pues, dos hermanos y dos ejemplos negativos de la figura del monarca: Iberio, que se deja llevar por la pasión, engaña e incumple la palabra dada a Isbela, abandona sus obligaciones de rey y vive escondido con su amada; y su hermano Ludovico, que representa al tirano arrogante y ambicioso:

$$
\begin{aligned}
& \text { Por mi corona que aquel } \\
& \text { que en algo me aconsejare } \\
& \text { en contra de lo que gusto, } \\
& \text { que yo mismo he de matarle } \\
& \text { con la vista solamente, } \\
& \text { que para vasallos tales } \\
& \text { no es menester el acero. }{ }^{23}
\end{aligned}
$$

Eso sí, destaca la generosidad del rey Iberio con su hermano Ludovico, ya que le perdona la traición e incluso comparte con él el reino, mientras que se comporta de manera cruel y despiadada con su prometida Isbela, víctima inocente de la historia ${ }^{24}$.

En Mudarse por mejorarse nos encontramos con el tema de la pasión ilícita de un príncipe por una dama prometida o casada. Este antiguo tema evoluciona desde planteamientos trágicos a finales del XVI a tratamientos más bien cómicos en la comedia nueva, como ocurre en este caso ${ }^{25}$. El conflicto de esta obra, que se desarrolla en el reino de Polonia, se produce cuando el príncipe sale de caza

23. Engañar para reinar, en Doce comedias de las más famosas que hasta ahora han salido, Lisboa, Antonio Álvarez, 1649, p. 176.

24. Para el engaño de Iberio a Isbela, vid. Glen F. Dille, «The Originality of Antonio Enríquez Gómez in Engañar para reinar», en Renaissance and Golden Age Essays in honor of D. W. McPheeters, ed. B. M. Damiani, Potomac, Maryland, Scripta Humanistica, 1986, p. 54-55.

25. Vid. Joan Oleza, «Reyes risibles/ reyes temibles: El conflicto de la lujuria del déspota en el teatro de Lope de Vega», en "Por discreto y amigo». Mélanges offerts à Jean Canavaggio, ed. C. Couderc y B. Pellistrandi, Madrid, Casa de Velázquez, 2005, p. 305-318. 
y queda prendado de una dama que contempla bañándose en una fuente. Para vengarse, su prometida Porcia se hace pasar por una dama extranjera llamada Laura, la dama de la fuente, y engaña al príncipe con un complicado enredo hasta que consigue que vuelva a sus brazos.

A lo que obligan los celos tiene lugar en Hungría y se desarrolla en un espacio rústico. El protagonista es un rey enamoradizo que, estando de cacería, se refugia en una granja en donde conoce y se enamora de una villana llamada Laura. Informado de que se trata en realidad de una duquesa, encarga a su privado Ricardo y a su hermano que la lleven a palacio, pero ellos intentan matarla. Finalmente, el rey se dará cuenta, por medio de una sortija, de que Laura era la misma dama que había deshonrado en la oscuridad ańos atrás y reparará su afrenta. El privado terminará desterrado del reino.

La comedia Celos no ofenden al sol se desarrolla en el reino de Sicilia y el motor de la acción son los celos que se propagan entre los protagonistas. La reina, instigada por el príncipe Federico, siente celos al creer que el rey ama a Rosaura y que Julio, criado del privado Alejandro, sirve de tercero. Por otra parte, Federico, príncipe y sucesor, se enfrenta a Alejandro y trata de engańar al rey, pero termina encarcelado. Será entonces Alejandro el que ocupe el puesto de privado, tal y como le anuncia el propio rey :

$$
\begin{aligned}
& \text { Yo te haré el mayor valido } \\
& \text { que alumbró el planeta rojo } \\
& \text { y en los anales del tiempo } \\
& \text { será tu nombre dichoso. }{ }^{26}
\end{aligned}
$$

Sin embargo, el criado Julio acrecienta los celos de la reina acusando a Rosaura. Al final de la segunda jornada se produce la boda de los protagonistas, Alejandro y Rosaura, impuesta por el rey. No obstante, Alejandro también sucumbe a la enfermedad de los celos y acepta la boda a regańadientes. Al final, se solucionan todos los conflictos y se alcanza el final feliz gracias a la confesión del traidor Federico y a la generosidad de Alejandro, que pide al rey que el príncipe sea perdonado.

Es evidente que el rey es sensato y prudente, combina la autoridad con la justicia y no se deja engańar por las trampas del traidor Federico ni por los celos desmedidos de la reina. En cambio, Alejandro, a pesar de su comportamiento ejemplar, termina por creer en la calumnia levantada a Rosaura e incluso llega a plantearse darle muerte.

Quien habla más obra menos se desarrolla también en Sicilia, en donde don Juan de Mendoza, caballero espańol, rivaliza con un duque por el amor de la princesa Diana. Por otra parte, Isabela, hermana de don Juan, ama al duque y trata de darle celos con el rey. Al final, se produce el desenlace feliz propiciado por el propio rey, que renuncia a Isabela para que esta se case con el duque, de quien está enamorada.

26. Celos no ofenden al sol, en Flor de las mejores doce comedias de los mayores ingenios de España..., Madrid, Diego Díaz de la Carrera, 1652, f. 88r. 
En el corpus de dramas y comedias historiales contamos con 13 obras en las que está presente la figura del monarca, aunque en algunos casos se limita a participar con más o menos protagonismo en una intriga amorosa. De nuevo lo que destaca es la variedad de soberanos que aparecen en escena. Por una parte, hay poderosos de la antigüedad clásica como la reina Helena en Los dos filósofos de Grecia, Filipo de Macedonia en El maestro de Alejandro y el emperador Marco Aurelio en Amar con vista y cordura. De nuestro pasado visigodo elige Enríquez Gómez a Leovigildo en Mártir y rey de Sevilla, San Hermenegildo. Un emperador de la China protagoniza la comedia en dos partes titulada Fernán Méndez Pinto, uno de sus primeros estrenos en 1633. También dedica una comedia a uno de los grandes modelos recientes: Las tres coronaciones de Carlos V. Pero la mayor parte de los monarcas pertenecen, como ocurre en otros dramaturgos de esta época, a la Edad Media española. Seis reyes toman protagonismo en sus comedias: Sancho I de Castilla (1065-1072) en $\mathrm{La}$ montañesa de Burgos, Alfonso VI (1072-1109) en El noble siempre es valiente, Fernando III el Santo (1230-1252) en El rey más perfecto, Alfonso X el Sabio (1252-1284) en No hay contra el honor poder, Pedro III de Aragón (1276-1285) en Los hermanos amantes y piedad por fuerza y Pedro I el Cruel (1350-1369) en A lo que obliga el honor y El Cardenal de Albornoz.

Dejaremos de lado el rey Alfonso VI, que aparece en El noble siempre es valiente, pero que no tiene demasiado protagonismo en la obra. Se trata de la versión dramática de la historia del Cid que más éxito tuvo en los escenarios y en las imprentas ${ }^{27}$.

En La montañesa de Burgos se dramatiza el conflicto entre un padre y un hijo, el rey Sancho y D. Fernando, que rivalizan en este caso por el amor de la villana Laura. En realidad, se trata de una hermana perdida y desconocida para el propio rey. D. Fernando siente celos de su padre, pero otro personaje le recuerda que se trata del rey y que «el gusto del rey, Fernando,/ es primero que la vida»; además, "obedecer / a los reyes es tener / licencia para vivir» ${ }^{28}$.

El modelo de príncipe cristiano se presenta en El rey más perfecto, en donde asistimos de nuevo al enfrentamiento entre un rey y un príncipe, en este caso Fernando III, proclamado en 1217 rey de Castilla, y su padre Alfonso IX de León. Fernando es coronado a pesar de las objeciones de D. Álvaro Núñez, enfrentado al Arzobispo de Toledo. Su padre le declara entonces la guerra. El comportamiento del rey Fernando es en todo momento virtuoso y modélico: busca la justicia («La buena razón de estado/ se ha de fundar en justicia»), no es partidario de la guerra («Nunca, señor, con violencia / se conquistan los estados») y se preocupa de los pobres y de los vasallos («El rey es el corazón / donde los vasallos mesmos, / como espíritus vitales / acuden a su medio»). Además, es generoso y clemente con el vencido: se encuentra a su padre

27. Vid. Rafael González Cañal, «Un éxito en los escenarios: El Cid Campeador de Antonio Enríquez Gómez», en Teatro español de los Siglos de Oro: dramaturgos, textos, escenarios, fiestas, dir. José María Díez Borque, Madrid, Visor, 2013, p. 77-98.

28. La montañesa de Burgos, op. cit., f. 30v y $31 \mathrm{r}$. 
derrotado en la batalla, le salva y le da la libertad. Posteriormente, el rey se comporta de manera ejemplar perdonando al traidor Álvaro Núñez, porque «el conservar los vasallos / fue siempre el mejor acuerdo» ${ }^{29}$. Al final, en un sueño premonitorio se le aparece la Fama que, tras la alabanza, pronostica sus victorias, mientras un moro le entrega las llaves de la ciudad de Sevilla.

En No hay contra el honor poder nos encontramos con Alfonso X y el príncipe Sancho. El príncipe pretende a $\mathrm{D}^{a}$ Blanca, esposa del valido D. Rodrigo de Lara. Para remediar la situación, el rey quiere casar al príncipe en Inglaterra, pero éste se vale del privado don Tello para seguir asediando a la dama. El rey Alfonso actúa en todo momento con equidad y trata de controlar al desbocado príncipe, el futuro Sancho el Bravo, y preservar el honor de D. Rodrigo.

El rey Pedro III de Aragón es el protagonista del drama historial Los hermanos amantes y piedad por fuerza. Trata de un rey que se deja llevar por la lujuria y compite con su propio hijo por el amor de una dama que ambos conocen en una aldea. El monarca utiliza todo tipo de artimañas para apartar a su rival: llega incluso a apresar al infante o trata de casarle con su prima Beatriz. No obstante, el rey es consciente de que no debe utilizar el poder para conseguir sus deseos: «que debemos ser los reyes / los primeros que las leyes / guardemos con más cuidado». El rey, cegado por la pasión, pierde el norte delante de la dama: «Mi vida pongo en tus manos / y mi reino pongo en ellas»; ante lo que el gracioso no se resiste a hacer el consabido comentario metateatral: «¡Qué requiebros tan usados / en los reyes de comedias! ${ }^{30}$. Finalmente, se entera de que la dama es en realidad una hija suya perdida e impide la relación entre los dos jóvenes para evitar el incesto.

Fue Pedro I el Cruel o el Justiciero uno de los reyes más representados en el teatro del siglo XVII. Se trataba de una figura histórica controvertida que se prestaba muy bien para la representación de variados conflictos dramáticos relacionados con la forma de ejercer el poder. Además, la leyenda creada sobre su figura servía para hablar de manera indirecta del presente. Así lo vemos, por ejemplo, en Las audiencias del rey don Pedro atribuida a Lope de Vega, o en su drama titulado Los Ramírez de Arellano, en donde recrea el enfrentamiento con su hermano y futuro rey Enrique II. Claramonte puso en escena los desmanes del rey don Pedro en Deste agua no beberé. Agustín Moreto presentó una imagen muy diferente del rey don Pedro en El valiente justiciero y ricohombre de Alcalá, destacando su apodo menos explotado, pues imparte justicia reparando los abusos de poder de un ricohombre que vejaba y abusaba de sus vasallos. En Ganar amigos, de Ruiz Alarcón, D. Pedro se convierte en un rey digno y respetable gracias a la influencia de su valido. La mayor parte de los dramaturgos de la época recogen en alguna obra las andanzas de este rey: Lope en La carbonera y en La niña de plata, Calderón en El médico de su honra, Vélez de Guevara en El diablo está en Cantillana, Pérez de Montalbán en La puerta Macarena, Hoz y

29. El rey más perfeto, op. cit., p. 58, 62, 116-118 y 134.

30. Los hermanos amantes y piedad por fuerza en Parte cuarenta de comedias de diversos autores, Madrid, Julián de Paredes, 1675, f. 139v-166v; las citas en los f. 141r y 147v. 
Mota en El montañés Juan Pascual, etc. Conservamos al menos dieciocho piezas de esta época que utilizan al rey Pedro I como personaje, bien presentando la visión de cruel o la de justiciero ${ }^{31}$.

Es importante recordar que su fama de cruel se generalizó a partir de la Crónica de los reyes de Castilla de Pero López de Ayala, escrita durante el reinado de su enemigo y sucesor Enrique II, a cuyo servicio trabajaba este canciller. Además, la leyenda se difundió también a través del romancero.

Son dos las comedias de Enríquez Gómez en las que aparece este rey: $E l$ gran Cardenal de España (escrita en 2 partes y estrenada en 1634) y $A$ lo que obliga el honor (impresa en 1642). En esta última asistimos al nacimiento de un tirano en la figura del príncipe D. Pedro. Se produce un anacronismo: Los hechos se desarrollan con D. Pedro como príncipe y, según los datos históricos, María de Padilla, también presente en la obra, conoció a Pedro I siendo ya rey, en el verano de 1352, durante una expedición a Asturias para luchar contra su hermanastro Enrique de Trastámara, tal y como relata López de Ayala. Doña María se convirtió en su amante, a pesar de que el rey acababa de casarse con doña Blanca de Borbón, y su relación duró bastante tiempo. El autor recupera este personaje para situarlo antes de la subida el trono de Pedro I en 1350.

Sin embargo, el príncipe muestra en esta obra un sincero amor por otra dama, doña Elvira, enturbiado por la inesperada decisión de su padre de casarla con D. Enrique. No quiere renunciar a su amor y busca todo tipo de estratagemas para verla, amparándose en su condición, mientras que doña María de Padilla, enamorada a su vez del príncipe, trata de impedir esta relación. D. Pedro trata de convencer a la dama de que hay una solución:

El tiempo, el poder y yo

somos poderosos dueños.

Cuando los esposos huyen a Sierra Morena, muestra su carácter más soberbio y orgulloso:

Don Pedro el Cruel me llaman,

soy príncipe, tengo amor,

y si don Enrique es noble,

primero he nacido yo.

El término cruel se repite a menudo en sus diálogos y parlamentos:

(La fuerza de la razón

reprime la majestad

y mi condición cruel.) $)^{32}$

31. Vid. José R. Lomba y Pedraja, «El rey D. Pedro en el teatro», en Homenaje a M. Pelayo en el año vigésimo de su profesorado, Madrid, Librería General de Victorino Suárez, 1899, II, p. 257-339; y Juan Matas Caballero, "La fuerza de las historias representada”. Reflexiones sobre el drama histórico: Los reyes de la historia de España en el teatro del Siglo de Oro», en Tiempo $e$ historia en el teatro del Siglo de Oro. Actas selectas del XVI Congreso internacional, ed. Isabelle Rouane Soupault y Philippe Meunier, Aix-en-Provence, Presses universitaires de Provence, 2015, p. 72-74. Para las obras de Lope de Vega sobre este monarca, vid. Frances Exum, The Metamorphosis of Lope de Vega's King Don Pedro, Madrid, Playor, 1974.

32. A lo que obliga el honor, ed. Rafael González Cañal, en A. Enríquez Gómez, Academias morales de las Musas, op. cit., I, p. 395, 450 y 423, respectivamente. 
Su sentimiento y el deseo un tanto obsesivo le lleva a arriesgarlo todo por la dama. Al final, se retira de escena tremendamente afligido por la muerte de dońa Elvira.

El rey es el personaje que desencadena la tragedia. Su bienintencionado intento de premiar a don Enrique dándole la mano de dońa Elvira será lo que provoque el conflicto posterior y, en última instancia, la muerte de la dama. Su intervención no solo no asegura bienestar a sus súbditos, sino que potencia la desgracia.

Pedro I el Cruel aparece también en la primera parte de El gran Cardenal de España, don Gil de Albornoz. Se trata de una obra elogiada por su amigo Fernández de Villarreal ${ }^{33}$.

Estamos ante una comedia de privanza. El protagonista es el arzobispo de Toledo D. Gil de Albornoz, que aparece como un gran valido honrado y atendido en un primer momento, pero más tarde derribado y desterrado del reino. Hasta ese momento ejerce como un gobernador de Castilla justo y prudente, incluso preocupado por la justicia social. El conflicto se desencadena con el enamoramiento entre Pedro I y dońa María de Padilla.

Las fuentes históricas fueron probablemente las obras de Juan Ginés de Sepúlveda, Historia de los hechos del cardenal D. Gil de Albornoz (Toledo 1606), y de Baltasar Porreño, Vida y hechos hazañosos del cardenal don Gil de Albornoz (Cuenca, 1626). Ambos escritores señalan como causa del destierro de D. Gil sus críticas a los amores del rey con doña María de Padilla. Sin embargo, el cardenal de Albornoz se marchó de España años antes de que D. Pedro conociera a la dama y entablara esta relación. En realidad, su partida fue provocada seguramente por su elevación al cardenalato. Al dramaturgo no le interesaba la verdad histórica y lo que buscaba, una vez más, era mostrar los peligros de un monarca que se dejaba llevar por las pasiones, algo parecido a lo que sucedía en la leyenda de los amores de Alfonso VIII y la judía de Toledo, dramatizada por Lope de Vega y Mira de Amescua.

Desde el principio se alude al poder que sobre el rey había adquirido su amante:

\author{
Es el alma \\ del rey; por ella gobierna, \\ de ella pende la esperanza \\ de Castilla. ${ }^{34}$
}

33. «La de El cardenal Albornoz manifestó, en su invención, disposición y conceptos, que no envidiara a los de aquellos que censuran todo lo que no pueden igualar. Unió en ella el decoro debido a un príncipe mozo, a los documentos de un ministro desinteresado, sin que las ternezas de amante mitigasen lo severo, ni lo maravilloso de lo escrito le hiciesen olvidar las advertencias de maestro; sin salir de la obediencia respetuosa en medio de una corrección arriesgada.» (Manuel Fernández de Villarreal, «Apología», en A. Enríquez Gómez, Academias morales de las Musas, op. cit., I, p. 260).

34. El gran cardenal de España don Gil de Albornoz, s. 1., s. i., s. a. (Madrid, BNE, sig. R/33890), f. 2r. 
Su padre, el rey Alfonso XI, ya se mostraba inquieto por la privanza de doña María:

$$
\begin{aligned}
& \text { la pena que llevo, hijo, } \\
& \text { atravesada en el alma } \\
& \text { es la que de vos me dicen } \\
& \text { los mismos que os acompañan, } \\
& \text { pues me aseguran que andáis } \\
& \text { tan inquieto que una dama } \\
& \text { gobierna vuestro albedrío: } \\
& \text { doña María, a quien llaman } \\
& \text { de Padilla, dicen que es. }{ }^{35}
\end{aligned}
$$

Se produce el inevitable enfrentamiento de don Gil y dońa María, y el arzobispo no puede menos que aconsejar al monarca que ponga freno a sus pasiones:

$$
\begin{aligned}
& \text { Ea, generoso Pedro, } \\
& \text { ea, señor, la lisonja } \\
& \text { cese, cese la amorosa } \\
& \text { voluntad de una belleza } \\
& \text { que os derriba y apasiona. } \\
& \text { Mirad que esta parte siempre } \\
& \text { ha sido ruina de todas } \\
& \text { las monarquías del mundo. }
\end{aligned}
$$

Este será el final para el valido, pues será desterrado del reino.

La personalidad de Pedro I el Cruel en esta obra es compleja ${ }^{37}$. Está hecho un mar de dudas y contradicciones respecto al privado. Además, hace esfuerzos por refrenar su tendencia a la violencia, pero al final sucumbe a la pasión y a la voluntad de Da María.

En otra comedia, Las tres coronaciones de Carlos V, vuelve a aludir Enríquez Gómez a este monarca, esta vez recordando una curiosa anécdota del momento de su muerte en Montiel, a manos de su propio hermano:

$$
\begin{aligned}
& \text { Al rey don Pedro el Cruel } \\
& \text { otro astrólogo entendido } \\
& \text { le dijo que moriría, } \\
& \text { por ser el hado preciso, } \\
& \text { en la torre de la estrella. } \\
& \text { Informose del aviso } \\
& \text { y no halló en todo su reino } \\
& \text { tal torre ni tal castillo, } \\
& \text { y el día que le mataron }
\end{aligned}
$$

35. Ibid., f. 3 r.

36. Ibid., f. 16v.

37. Vid. Ann L. Mackenzie, "Una comedia casi perdida y desconocida sobre El gran cardenal de España, don Gil de Albornoz», en El mundo del teatro en su Siglo de Oro: ensayos ofrecidos a John E. Varey, ed. José María Ruano de la Haza, Ottawa, Dovehouse, 1989, p. 389. 
halló en Montiel escrito un letrero sobre el fuerte que decía: «Este obelisco es la torre de la estrella.» ${ }^{38}$

\section{Conclusiones}

Como hemos visto, el rey es uno de los personajes más frecuentes en el teatro de Enríquez Gómez. La preocupación por el poder y sus entresijos es permanente en la obra dramática del criptojudío conquense. Tanto en sus comedias palatinas como en los dramas historiales, reyes, príncipes y validos toman un protagonismo notable. Encontramos en sus obras dos enfrentamientos recurrentes:

Rey / príncipe: este conflicto paternofilial ${ }^{39}$ aparece en siete comedias (Mudarse por mejorarse, No hay contra el honor poder, Amor con vista y cordura, A lo que obliga el honor, etc.). Unas veces el enfrentamiento es por el poder y la sucesión al trono (El rey más perfecto) y en otros casos la rivalidad entre padre e hijo se produce por una dama (La montañesa de Burgos y Los hermanos amantes $y$ piedad por fuerza).

Rey / valido: en otras siete comedias se ponen en escena las difíciles relaciones entre el rey y el valido. Así ocurre en dos comedias palatinas (A lo que obligan los celos y Celos no ofenden al sol) y en cinco comedias de asunto histórico (Fernán Méndez Pinto, El gran Cardenal de España, El maestro de Alejandro, No hay contra el honor poder y La montañesa de Burgos).

Por tanto, es evidente que Enríquez Gómez, como muchos de sus coetáneos, estaba preocupado por el comportamiento de los reyes, por los límites del poder real y por el tema de la educación del príncipe, además de reflexionar a menudo sobre la conflictiva relación entre el rey y el valido, tan de actualidad en la España de los Austrias. A través de sus comedias palatinas y de sus dramas historiales, en donde se exhiben todo tipo de comportamientos de los monarcas, el dramaturgo conquense difundió también su pensamiento político.

No obstante, tomadas en conjunto, sus obras dramáticas no proyectan una imagen negativa de reyes y príncipes, pues predominan aquellos que se comportan de manera digna. Incluso llega a presentar un modelo ejemplar de monarca en la figura de Fernando III el Santo, protagonista de El rey perfecto. Los casos más negativos son el soberbio Nembrot, del que no hemos tratado, el ambicioso rey Ludovico de Engañar para reinar o el insidioso príncipe Federico de Celos no ofenden al sol. Otros reyes y príncipes son criticados por dejarse

38. Las tres coronaciones de Carlos V en Parte cuarenta de comedias nuevas de diversos autores, Madrid, Julián de Paredes, 1675, f. 125v. El castillo de Montiel se llama actualmente castillo de la Estrella.

39. También es un tema muy del gusto de Rojas Zorrilla; vid. Teresa Julio. "No hay para un padre reposo": conflictos paternofiliales en las comedias cainitas de Francisco de Rojas Zorrilla", Anagnórisis. Revista de investigación teatral, no 11, 2015, p. 6-19. 
llevar por las pasiones y atropellar el honor de damas y maridos: Pedro I en brazos de doña Elvira o de doña María de Padilla; Sancho II de Castilla y Pedro III enamorados de sendas villanas, que al final resultan ser de su propia sangre; o un príncipe, el futuro Sancho el Bravo, enamorado de la esposa del valido Rodrigo de Lara.

No hay que olvidar que por medio de la ficción teatral el autor establecía un diálogo con la realidad de su tiempo y, probablemente, muchas de las críticas y de las situaciones que aparecían en escena aludían indirectamente a problemas de la monarquía y de la sociedad española del siglo XVII. Enríquez Gómez no tuvo fácil su integración social y llevó una vida clandestina llena de infortunios y adversidades. Todo ello le condujo a la reflexión sobre las diversas instancias del poder y sobre las figuras del rey y de los ministros, como se aprecia en obras como Luis dado de Dios y la Política angélica, ambas publicadas fuera de España. No es de extrañar, pues, que sus obras dramáticas también se hallen impregnadas de buena parte de las ideas políticas que preocupaban al judeoconverso conquense. 
